\title{
Mother-to-child transmission of HIV-I drug resistance in a French cohort
}

\author{
Frédéric Benizri*1, Véronique Schneider ${ }^{1}$, Ali Kara ${ }^{1}$, Sabine Guessant ${ }^{1}$, Anne- \\ Geneviève Marcelin², Roland Tubiana2 ${ }^{2}$, Marie-Dominique Tabone ${ }^{3}$, \\ François Hervé ${ }^{1}$, Geneviève Vaudre ${ }^{3}$, Axelle Dehee ${ }^{3}$, Guy Leverger ${ }^{3}$ and \\ Catherine Dollfus ${ }^{3}$
}

\author{
Address: ${ }^{1} \mathrm{APHP}$, Tenon hospital, Paris, France, ${ }^{2} \mathrm{APHP}$, Pitié Salpêtrière hospital, Paris, France and ${ }^{3} \mathrm{APHP}$, Armand Trousseau hospital, Paris, \\ France \\ * Corresponding author
}

\author{
from Fourth Dominique Dormont International Conference. Host-Pathogen Interactions in Chronic Infections \\ Paris, France. 13-15 December 2007 \\ Published: 9 April 2008 \\ Retrovirology 2008, 5(SuppI I):PI0 doi:10.1 I86/1742-4690-5-SI-PI0
}

This abstract is available from: http://www.retrovirology.com/content/5/SI/PIO

(C) 2008 Benizri et al.; licensee BioMed Central Ltd.

\section{Background}

The use of antiretroviral drug therapies in HIV-1 infected pregnant women and their infants has resulted in significant reductions in the rates of mother-to-child transmission (MTCT), although emerging resistances become a growing concern. The aim of this study was to characterize resistance patterns of HIV-1 strains for mother-infant pairs among the residual cases of vertical transmission.

\section{Materials and methods}

HIV-1 infected infants by vertical transmission diagnosed in their first year of life in a single teaching hospital and born between January 1997 and May 2006 were enrolled. Viral genotypes were performed on available samples of plasma RNA-HIV, at the time of diagnosis for infants and the closest possible to delivery in their respective mothers. HIV-1 genotype drug resistance interpretation was based on the ANRS algorithm of July 2006. Whenever possible, genotypic drug resistance profile of HIV-1 was also obtained for the father.

\section{Results}

18 mother-infant pairs were included, 11 identified through MTCT prevention follow-up (MTCT rate: 11/ $947=1.2 \%$ ), 7 cases in various contexts with mothers diagnosed for HIV-1 beyond delivery. Samples were available for genotypes in 14 of them. In 4/14 (29\%) infected HIV-
1 newborns, resistant virus to at least one antiretroviral drug were observed. For these four cases, two genotypic analyses of the father supplemented the analysis of mutation transmission.

In the first mother-infant pair, mutation $\mathrm{M} 184 \mathrm{~V} / \mathrm{M}$ was identified in the sample of the newborn (unexposed postnatally to 3TC) at 14 days of life although not detected in its mother's sample at 40 days before delivery. In the second mother-infant pair, poor compliance of multitreated woman explained vertical transmission of multidrugresistant HIV-1 (AZT, 3TC and IP). In the third case, identical mutations conferring resistance to AZT (T215Y) and NNRTI (K103N+Y181V) were observed in the infant and both parents. The last case resulted from a documented primary HIV-1 infection in late pregnancy with vertical transmission of a K101E resistant mutation isolated also in father and mother, both being naïve to ARVs.

\section{Conclusions}

Over almost 10 years, 18 cases of vertical transmission of HIV-1 were registered in this cohort with an important proportion of infected infants who acquired drug-resistant virus $(4 / 14-29 \%)$. The results of this study raise the importance of HIV screening of pregnant women and partners. Viral genotyping can guide prophylaxis regimen and/or treatment of infected infants. 